\title{
Molecular Surface Chemistry by Metal Single Crystals and Nanoparticles from Vacuum to High Pressure
}

\author{
Gabor A. Somorjai ${ }^{1,2, *}$ and Jeong Y. Park ${ }^{1,2}$ \\ ${ }^{1}$ Department of Chemistry, University of California, Berkeley, CA 94720 \\ ${ }^{2}$ Materials Sciences Division and Chemical Sciences Division, Lawrence Berkeley \\ National Laboratory, Berkeley, CA 94720
}

\begin{abstract}
Model systems for studying molecular surface chemistry have evolved from single crystal surfaces at low pressure to colloidal nanoparticles at high pressure. Low pressure surface structure studies of platinum single crystals using molecular beam surface scattering and low energy electron diffraction techniques probe the unique activity of defects, steps and kinks at the surface for dissociation reactions $(\mathrm{H}-\mathrm{H}, \mathrm{C}-\mathrm{H}, \mathrm{C}-\mathrm{C}, \mathrm{O}=\mathrm{O}$ bonds). High-pressure investigations of platinum single crystals using sum frequency generation vibrational spectroscopy have revealed the presence and the nature of reaction intermediates. High pressure scanning tunneling microscopy of platinum single crystal surfaces showed adsorbate mobility during a catalytic reaction. Nanoparticle systems are used to determine the role of metal-oxide interfaces, site blocking and the role of surface structures in reactive surface chemistry. The size, shape and composition of nanoparticles play important roles in determining reaction activity and selectivity.
\end{abstract}

*To whom correspondence should be addressed. E-mail: somorjai@ berkeley.edu 


\section{Introduction}

Much of the research by Gerhard Ertl's group is focused on vacuum studies of reactive chemistry on single crystal surfaces, with a special emphasis on chemisorption ${ }^{1}$, 2 . During the last forty years, both molecular surface science and surface technologies underwent explosive development ${ }^{3}$. Instruments are now available that permit atomic scale analysis of the structure and composition of surfaces in a vacuum and at solid-gas and solid-liquid interfaces during active catalytic reactions ${ }^{4,5,6,7}$.

The three types of surfaces studied are shown in Figure 1. External surfaces are generally single crystals (Figure 1a) ${ }^{8}$. Internal surfaces are where most of the surface area is located inside the micropores or mesopores ${ }^{9,10}$. These surfaces may contain metal nanoparticles for catalytic purposes (Figure 1b). Nanoparticles are fabricated by lithography techniques or synthesized in colloidal solutions (Figure 1c) ${ }^{11-13}$.

The current technologies developing most rapidly within modern surface chemistry are shown in Figure $2^{14}$. These applications include catalysis, biointerfaces, electrochemistry and corrosion. The properties and technologies based on these properties can now be revisited, allowing for studies and increased understanding on the molecular scale. For example tribology, the science of friction, lubrication and wear, has experienced a renaissance with the development of new technologies of superior lubricants, wear-resistant coatings, and new nanotribological tools such as friction force microscopy ${ }^{15,16}$.

This review focuses on the catalytic reactivity of platinum to show how the evolution of molecular surface chemistry led to more advanced applications of this metal. Platinum is the grandfather of all catalysts and is outstanding for carrying out many chemical reactions. It was first used in 1823 to produce flames, aiding the combustion of hydrogen in air. Paul Sabatier compiled a book on organic reactions accelerated by platinum at the end of the $19^{\text {th }}$ Century ${ }^{17,18}$. Today, platinum is the main component of the catalytic converter in automobiles that cleans the exhaust gases. The metal is also used to produce high-octane gasoline from naphtha.

Our studies indicate that the platinum surface restructures during catalytic reactions. It has a different structure when it carries out oxidation reactions than when it 
rearranges organic molecules. This chameleon-like behavior makes it very versatile in

many catalytic reactions ${ }^{19-21}$. Three aspects of the study of molecular surface chemistry of the metal are highlighted here; the study of platinum single crystal surfaces in a vacuum, the catalytic activity of platinum single crystal surfaces in high pressures and the synthesis, characterization and catalytic reactions on platinum nanoparticles $1-10 \mathrm{~nm}$ in size.

\section{The Study of Platinum Single Crystal Surfaces in a Vacuum and at Low $\left(<10^{-5}\right.$ Torr) Pressures}

\section{II.a. Low energy electron diffraction (LEED)}

The surface structure of clean surfaces and adsorbed molecules were uncovered using Low energy electron diffraction (LEED) surface crystallography ${ }^{8,} 22,23$. A schematic of LEED is shown in Figure 3a. The small $\left(\sim 1 \mathrm{~cm}^{2}\right)$ single-crystal sample is cleaned in an ultrahigh vacuum chamber, usually using a chemical wash or ionbombardment. Afterwards, the crystal is heated to permit the ordering of surface atoms through diffusion to equilibrium positions. An electron beam, in the energy range of 10$200 \mathrm{eV}$, is back-scattered from the surface and detected as a function of energy and angle. Due to the small mean free path of low energy electrons, this technique is sensitive to the atomic surface arrangement. Figure $3 b$ show the LEED patterns of $\operatorname{Pt}(111)$ and $\operatorname{Pt}(557)$ surfaces representing the hexagonal and stepped surface structures.

LEED surface crystallography studies resulted in the discovery of the reconstruction of clean surfaces. A surface is formed by cutting through the solid parallel to a chosen plane of atoms. Surface reconstruction is caused by the asymmetry of the atomic arrangement at the interface, leading to a change in the electronic states near and at the surface that reduces surface free energy. This results in a change in the equilibrium position of surface atoms. Figure $4 \mathrm{a}$ shows the surface reconstruction of the clean $\mathrm{Pt}$ $(100)^{24}$ surface to the $(1 \times 5)$ surface structure. 
By monitoring the intensity of the diffracted beams as a function of their kinetic energy, the surface structure of many organic molecules, such as ethylene on Pt (111), was determined ${ }^{25}$. The surface structure includes such details as precise bond distances and bond angles. Figure $4 \mathrm{~b}$ shows metal surface restructuring induced by ethylene $\left(\mathrm{C}_{2} \mathrm{H}_{4}\right)$ adsorption in the form of ethylidyne $\left(\mathrm{C}_{2} \mathrm{H}_{3}\right)$, indicating that the adsorbate-surface interaction induces both the molecular rearrangement of the adsorbate and the reconstruction of metal surfaces around the adsorption site. These studies and others ${ }^{25}$ show that adsorbate-induced restructuring of metal surfaces form configurations similar to metal-organic complexes.

\section{II. b. Molecular beam surface scattering}

Parallel with these studies of surface structures, molecular beam surface scattering was developed and used for studying reactions and energy transfer between incident molecules and the metal surface atoms ${ }^{26}$. A well-collimated beam of molecules with a uniform and known translational energy and known rotational and vibrational state populations strikes a clean metal surface. Some of the molecules are back-reflected after a very short residence time, while others are trapped for much longer times before desorbing. By measuring the amount of translational energy exchanged by detecting the velocity and angular distribution of the scattered molecules with a suitable time-of-flight analysis, the gas-surface energy transfer process can be described. Figure 5a shows a schematic of molecular beam surface scattering where the beams of molecules are directed towards the surface.

Figure $5 \mathrm{~b}$ shows molecular beam scattering results from studies of $\mathrm{H}_{2}-\mathrm{D}_{2}$ exchange. These results indicate that atomic steps on metal surfaces break chemical bonds, in this case hydrogen-hydrogen bonds, with unit reaction probability. That is, every hydrogen molecule dissociated when scattered from the stepped platinum surface. When a defect-free platinum (111) crystal face was studied, the dissociation probability of molecular hydrogen was below the detection limit of $10^{-3} 27$. Combined molecular beam surface scattering and LEED-surface structure studies revealed the unique activity 
of defects, atomic steps and kinks on metal surfaces in dissociating $\mathrm{H}-\mathrm{H}, \mathrm{C}-\mathrm{H}, \mathrm{C}-\mathrm{C}, \mathrm{C} \equiv \mathrm{O}$ and $\mathrm{O}=\mathrm{O}$ bonds.

\section{Catalytic Activity of Platinum Single Crystal Surfaces at High Pressures}

\section{III.a. Development of instruments for high pressure studies}

Catalytic reactions cannot be fully studied in a vacuum because of the very low reaction probability inhibiting their detection. Techniques utilized to study surfaces under pressure have been developed. This review highlights three techniques developed for studying surfaces at high pressure: a high pressure-ultra high vacuum combined system, sum frequency generation (SFG) vibrational spectroscopy and scanning tunneling microscopy. Schematics of these three techniques are shown in Figure 6.

A high pressure-ultra high vacuum combined system permitted both reaction studies at high pressures and surface analysis, which needed vacuum before and after reactions (Figure 6a). Using these hybrid systems, we investigated various catalytic reactions, including ammonia synthesis on iron, rhenium crystal surfaces and hydrocarbon conversion reactions over platinum. The reaction rate and product composition was found to depend upon the surface structure ${ }^{28}$.

SFG vibrational spectroscopy is a surface-specific optical technique (Figure 6b) ${ }^{6}$, $29,30,31,32$. One or both laser frequencies are tuned and overlapped both spatially and temporally on the surface of interest. SFG is a second-order nonlinear optical process, and as such a signal is forbidden from a centrosymmetric medium, such as the bulk of face centered cubic crystals or an isotropic high pressure gas or a liquid ${ }^{33,34}$. However, at the surface or interface, the second order susceptibility is non-zero. The overall efficiency of the SFG process will be enhanced when one of the beams is in resonance with a vibrational level of a species at the interface. By scanning one of the lasers in the infrared frequency regime, a sum frequency signal can be obtained, and the surface yields a vibrational spectrum that is sensitive only to molecules adsorbed on the surface. This signal is in the visible frequency range. 
High pressure scanning tunneling microscopy (HPSTM) provides atomically resolved images of surfaces under high gas pressures and during catalytic reactions ${ }^{35-37}$ (Figure 6c). While most spectroscopic techniques yield time-averaged information of structure and bonding, STM detects surface dynamics when motion of adsorbates and metal atoms occurs at speeds comparable to or less than the scan rate of approximately 10 $\mu \mathrm{m} / \mathrm{s}$.

\section{III.b. Study of benzene hydrogenation with high pressure techniques}

SFG vibrational spectroscopy and high pressure STM were used to monitor the surface reaction intermediates and surface mobility during benzene hydrogenation ${ }^{38}$. Benzene hydrogenation is an industrially relevant reaction in petroleum refining and downstream chemical processing and has two products: cyclohexene and cyclohexane. SFG vibrational spectroscopy under high-pressure benzene hydrogenation revealed three characteristic vibrational bands on the $\mathrm{Pt}$ (111) surface, H-C-C-, vinylic ( $\mathrm{H}-\mathrm{C}=\mathrm{C}-)$, and physisorbed benzene bands (Figure 7a) ${ }^{38,39}$.

Interestingly, when the surface is scanned during the reaction turnover of benzene hydrogenation, no scanning tunneling microscopy pictures are seen. Large scale images $(\sim 1000 \AA)$ still reveal the same platinum steps regularly observed, but no molecular surface structure can be resolved (Figure 7b). This indicates that the adsorbed monolayer of molecules and atoms is now too mobile to be imaged with STM. The maximum scanning speed at which high resolution images can be obtained is $10 \mathrm{~nm} / \mathrm{msec}$, but several scans may be necessary to image an entire molecule. Molecules that diffuse or adsorb/desorb on a faster time scale than this are not able to be resolved. The formation of this mobile overlayer also corresponds to the onset of catalytic activity, as monitored by the mass spectrometer ${ }^{37}$. Once the reaction stops due to surface poisoning by carbon monoxide, ordered structures form and no reaction product is formed (Figure 7c). The high-coverage pure $\mathrm{CO}$ structure corresponds to the $(\sqrt{ } 19 \times \sqrt{ } 19) \mathrm{R} 23.4^{\circ}$ structure $^{40}$. All benzene adsorbates have been displaced by the strongly bound and closely packed $\mathrm{CO}$ molecules. The high mobility of adsorbates on the surface under reaction conditions is important in freeing up active sites, which results in catalytic turnover. 


\section{Synthesis, Characterization and Catalytic Reactions on Platinum Nanoparticles in the 1-10 nm Range. Influence of Size, Shape and Support}

\section{IV.a. Synthesis of Pt nanoparticles and development of 2D and 3D nanoparticle arrays}

Model single crystal catalysts cannot identify all of the active sites that are important for catalytic selectivity, since catalysts are usually nanoparticles supported on oxide surfaces. Therefore, we developed model nanoparticles by lithography techniques and colloid chemistry-controlled nanoparticle synthesis (Figure 1c and Figure 8). These nanoparticles are placed on a Langmuir-Blodgett trough and pulled as a monolayer film at various densities. This approach allows two-dimensional metal nanoparticle arrays to be formed $^{41}$. The average inter-particle spacing can be tuned by varying surface pressure. This approach has the advantage that size and composition of the nanoparticles can be controlled. The formation of an oxide-metal interface between nanoparticles and substrate can also be obtained when synthesized using this colloidal process. Various surface techniques, such as X-ray photoelectron spectroscopy (XPS) and atomic force microscopy (AFM), can be utilized to characterize chemical composition and morphology of 2D nanoparticle arrays before and after chemical reactions. Figure 8 shows an SEM image of hexadecylthiol-capped Pt nanoparticle arrays on a silicon wafer. Nanoparticles can be incorporated in mesoporous high surface area oxides such as SBA-15 ${ }^{42}$. A TEM image of platinum nanoparticles encapsulated in mesoporous silica with a channel structure (SBA15 ) is also shown in Figure 8. This process forms a 3-dimensional model catalyst system with high surface area $\left(>1 \mathrm{~m}^{2} / \mathrm{g}\right)$.

With stabilizing agents, the colloid nanoparticles permit us to control the size and shape that are required to precisely quantify catalytic influences. This is in contrast to the approach using Pt clusters to prepare conventional oxide-supported Pt catalysts that have been used for several decades. The nanoparticles created are within a single crystalline domain, meaning the particles can be created with a precise control of both shape and size. This allows for very controlled experiments that answer questions about the roles of steps 
and kinks as reactive sites, as well as better understanding of the role surface structure plays in determining catalytic activity and selectivity. The porous nature of capping layers allows the reactants and products to travel through the capping layer, exhibiting reproducible measurements of turnover rate.

Our focus was to create platinum, rhodium or bimetallic nanoparticles that can be produced with monodispersity and well-controlled shape ${ }^{34,42,43}$. Using hexachloro platinic acid or rhodium acetyl-acetonate as a precursor monomer, we could produce monodispersed metal nanoparticles that were individually coated with a polymer cap to prevent aggregation in solution. As the particles nucleate and grow, they are held in a polymer with pores sized to allow growth to 1-8 $\mathrm{nm}$ as shown in Fig 9a. Particle size is controlled by the monomer concentration. With suitable changes to the growth parameters, the shape of these particles is controlled. Figure 9b shows cubic, cuboctahedral, and porous Pt nanoparticles prepared using tetradecyltrimethylammonium tromide (TTAB) as a surface-stabilizing reagent. By changing the $\mathrm{pH}$ value of the $\mathrm{NaBH}_{4}$ (reducing solution which contributes to control of the reduction rate), shape evolution from cuboctahedra to cubes was observed. Porous particles were obtained by reduction in ascorbic acid.

\section{IV.b. Influence of size, shape and composition of metallic nanoparticles on the activity and selectivity}

\section{Size dependence of Pt nanoparticles}

Reaction selectivity is a major focus of $21^{\text {st }}$ century catalysis science. That is, if there are several thermodynamically stable products, only one desired product is formed 44-46. We have investigated some typical multipath reaction selectivities: benzene and cyclohexene hydrogenation. Reaction selectivity is much less understood than reaction activity of single-product catalytic reactions, such as ammonia synthesis or ethylene hydrogenation. A very small change in competing potential energy barriers changes the product selectivity dramatically. These changes can be caused by structural changes or the use of additives. 
Figures $10 \mathrm{a}$ and $10 \mathrm{~b}$ shows reaction selectivity and activation energy for cyclohexene hydrogenation/dehydrogenation on Pt nanoparticles in SBA-15 as a function of particle size. These results show that benzene formation declines as particle size increases, while cyclohexene formation remains unchanged with changes in particle size. The activation energy for dehydrogenation to benzene increases with increasing particle size. This result implies that the size of the nanoparticles is important for control of reaction selectivity.

\section{Shape dependence of Pt nanoparticles}

We studied the form of benzene hydrogenation that produces cyclohexane and cyclohexene on the platinum (111) surface and cyclohexene on the (100) face. SFG studies on platinum (100) and (111) identified $\pi$-allyl $c-\mathrm{C}_{6} \mathrm{H}_{9}$ as the most abundant

reactive intermediate ${ }^{47}$. This reaction intermediate was found on the $\operatorname{Pt}(100)$ surface, but not on the Pt (111) surface. This indicates that adsorbed cyclohexene more readily dehydrogenates to form $\pi$-allyl $c-\mathrm{C}_{6} \mathrm{H}_{9}$ on the $\operatorname{Pt}(100)$ surface than on the $\operatorname{Pt}(111)$ surface.

This face specificity of benzene hydrogenation makes it suitable for probing nanoparticle shape-dependent reaction selectivity. Benzene hydrogenation studies on cubooctahedra and cubic Pt nanoparticles demonstrated that cyclohexene and cyclohexane formed on cuboctahedral nanoparticles, while only cyclohexane formed on cubic nanoparticles, consistent with previous results for single-crystal Pt surfaces (Figure 11) ${ }^{46}$. This study indicates the importance of nanoparticle shape in determining reaction selectivity.

\section{Composition dependence of catalytic reaction rates of bimetallic nanoparticles}

Composition is another important factor that influences catalytic activity and selectivity. Pt-Rh bimetallic nanoparticles with variable composition and constant size (9 
$\pm 1 \mathrm{~nm}$ ) were synthesized by a one-pot polyol synthetic method ${ }^{48}$. The activity of CO oxidation on these bimetallic nanoparticles was studied ${ }^{49}$.

Colloid techniques are used to take chloroplatinic acid or a rhodium precursor (like rhodium acetyl/acetonate), and in the presence of a polymer (PVP). These metal ions are then reduced in alcohol. Figure 12b shows the TEM images of monodispersed $\mathrm{Rh}_{0.4} \mathrm{Pt}_{0.6}$ nanoparticles. The size was $9.3 \pm 1.2 \mathrm{~nm}$, which was determined by measuring 150 nanocrystals from a TEM image. Once monodispersed particles with the desired size and composition are obtained, we can put them in a Langmuir trough and apply a certain surface pressure to deposit different densities of nanoparticle monolayer films. Figure $12 \mathrm{~b}$ shows the XPS spectra measured on two dimensional $\mathrm{Rh}_{\mathrm{x}} \mathrm{Pt}_{1-\mathrm{x}}(\mathrm{x}=0-1)$ nanoparticle arrays on a silicon surface. We found that the intensity of the Rh3d peak increases, while the Pt4f and Pt4d peaks decrease as the composition of Rh increases.

We found that the turnover rate of a pure $\mathrm{Rh}$ nanoparticle is 20 times that of a $\mathrm{Pt}$ nanoparticle under the reaction conditions used (100 Torr $\mathrm{O}_{2}, 40$ Torr $\mathrm{CO}$ at $180{ }^{\circ} \mathrm{C}$ ). $\mathrm{Rh}_{\mathrm{x}} \mathrm{Pt}_{1-\mathrm{x}}(\mathrm{x}=0.2-0.8$ ) particles exhibit an intermediate activity as shown in Figure 12c, while the activation energy increases from 25 to $27 \mathrm{kcal} / \mathrm{mol}$ with increasing rhodium content.

The observation that pure $\mathrm{Rh}$ nanoparticles are more reactive than Pt nanoparticles is consistent with the earlier CO oxidation studies on thin films ${ }^{50}$ and single crystals ${ }^{30,51}$. It is associated with differences in the initial dissociative sticking probability of oxygen $(\mathrm{Pt}$ is 0.2 and $\mathrm{Rh}$ is 1.0$)^{52,53}$. As shown in Figure 12c, the reactivity of CO oxidation increases nonlinearly as a function of Rh composition. This tendency could be due to preferential migration of Pt to the surface, giving rise to a higher surface concentration of Pt compared to the bulk concentration ${ }^{54}$. The results demonstrate the possibility of controlling catalytic activity in metal nanoparticle-oxide systems via tuning the composition of the nanoparticles.

\section{Correlations and Future Directions}

It is necessary to use in-situ, surface sensitive techniques (SFG and STM), to monitor nanoparticles as they undergo reactions, just as single crystal surfaces were 
monitored during chemical reactions ${ }^{34}$, as shown in the schematic in Figure 13. The SFG studies of pyridine hydrogenation were successful in detecting pyridinium cation $\left(\mathrm{C}_{5} \mathrm{H}_{5} \mathrm{NH}^{+}\right)$reaction intermediates on TTAB covered platinum nanoparticles and the formation of fully hydrogenated piperidine molecules as reaction products in the gas phase ${ }^{55}$. Preliminary studies using STM indicate that the metal nanoparticles cannot be imaged because of the polymer capping. Work is in progress to remove the polymer capping to prepare the exposed nanoparticles for STM studies.

Enzyme catalysts, homogeneous or heterogeneous catalysts are all nanoparticles. For example, cytochrome $\mathrm{C}$ has a $4 \mathrm{~nm}$ catalytic site, where inside the protein ligands are $1.4 \mathrm{~nm}$ in size. A single site olefin polymerization catalyst, which is homogeneous, is 1.6 $\mathrm{nm}$ in size. Platinum nanoparticles are available that are active in the $1-10 \mathrm{~nm}$ regime.

Nature and technology produce catalysts in nanometer scales because the small number of atoms permits the flexible rearrangement of atomic position in the catalyst. Rearranging the catalyst surface requires breaking metal-metal bonds that requires energy. When a metal atom has fewer neighbors, as would be the case in a nanoparticle, less energy is required for rearrangement to occur. The reacting molecules, reaction intermediates and products must alter their bond distances to rearrange rapidly. Reaction is favored when relatively small number of bonds of the reacting molecules to be broken and reformed. Catalysis takes place more easily in a nanoparticle form, where less atoms and molecules participate in the restructuring during the catalytic turnover. The unique catalytic properties of nanoparticles and capability of controlling catalytic activity and selectivity by tuning their shape, size and composition can bring new opportunities in fundamental understanding of molecular surface chemistry and in major chemical energy conversion technologies.

\section{Acknowledgement}

This work was supported by the Director, Office of Science, Office of Basic Energy Sciences, Division of Materials Sciences and Engineering of the U.S. Department of Energy under Contract No. DE-AC02-05CH11231. 


\section{Figure Captions}

Figure 1. The three types of surfaces studied. (a) External surfaces: Platinum (111) surface. (b) Internal surfaces: the surface area located inside the structure, such as mesoporous silica. (c) Nanoparticles: atomic force microscopy (AFM) image of platinum nanoparticles made by electron beam lithography; transmission electron microscopy (TEM) image of cubic nanoparticles synthesized in colloidal solutions.

Figure 2. The current technologies developing most rapidly within modern surface chemistry

Figure 3. (a) Schematic of LEED instrumentation and (b) LEED patterns on $\operatorname{Pt}(111)$ and $\operatorname{Pt}(755)$ surfaces.

Figure 4. (a) Surface reconstruction of $\mathrm{Pt}(100)$ revealed with LEED. (b) Illustration of adsorbate-induced restructuring of metal surfaces for ethylene on Pt (111).

Figure 5. (a) Schematic of molecular beam scattering studies. Detection of the scattered beam, desorbed reaction products or adsorbed species permits an understanding of the interaction between molecules and the surface. (b) High reactivity of $\mathrm{H}_{2}-\mathrm{D}_{2}$ exchange revealed by molecular beam scattering.

Figure 6. (a) Photograph of a high pressure-ultra high vacuum combined system. The high-pressure cell is shown in both the open (top) and closed (bottom) positions. Schematics of (b) high pressure sum frequency generation (HP-SFG) vibrational spectroscopy and (c) high pressure scanning tunneling microscopy (HP-STM).

Figure 7. (a) SFG spectra of benzene hydrogenation on $\operatorname{Pt}(111)$ surface. The reaction occurs in excess hydrogen of about 100 Torr and 10 Torr of benzene. SFG vibration spectra reveal that the presence of three different species on the surface in this reactant mixture: H-C-C-, vinylic (H-C=C-), and physisorbed benzene bands. (b) $20 \mathrm{~nm}$ x $20 \mathrm{~nm}$ 
STM images of Pt(111) in the presence of 10 Torr of benzene, 100 Torr of $\mathrm{H}_{2}$, and 650 Torr of Ar at $353 \mathrm{~K}$. (c) $20 \mathrm{~nm} \times 20 \mathrm{~nm} \mathrm{STM}$ image of Pt(111) in the presence of 10 Torr of benzene, 100 Torr of $\mathrm{H}_{2}$, and 630 Torr of Ar heated to $353 \mathrm{~K}, 5$ Torr of $\mathrm{CO}$ added, and cooled to $298 \mathrm{~K}$.

Figure 8. Evolution of model surfaces from single crystal Pt surfaces to nanoparticle arrays supported in two- or three-dimensional oxide structures. An SEM image of twodimensional (2D) nanoparticle arrays and a TEM image of three-dimensional (3D) arrays are shown.

Figure 9. (a) TEM images of Pt nanoparticles with various sizes capped with PVP poly (vinylpyrrolidone). Size of nanoparticles can be controlled within the range of $1.7 \sim 7.1$ $\mathrm{nm}$. The scale bars refer to $10 \mathrm{~nm}$. (b) TEM image of Pt nanoparticles with different shapes (cube, cuboctahedra, and porous particles) stabilized with TTAB. The scale bar in the images refer to $20 \mathrm{~nm}$.

Figure 10. Size dependence of Pt nanoparticles on the selectivity and activation energy for (a) cyclohexene hydrogenation and (b) cyclohexene dehydrogenation.

Figure 11. Structural dependence of selectivity in benzene hydrogenation. Benzene hydrogenation studies demonstrated that both cyclohexene and cyclohexane formed on cuboctahedral nanoparticles and only cyclohexane formed on cubic nanoparticles, consistent with previous results for single-crystal Pt surfaces.

Figure 12. (a) The XPS plots measured on two dimensional $\mathrm{Rh}_{\mathrm{x}} \mathrm{Pt}_{1-\mathrm{x}}(\mathrm{x}=0-1)$ nanoparticle arrays on a silicon surface. (b) TEM images of the $\mathrm{Rh}_{0.4} \mathrm{Pt}_{0.6}$ nanoparticles. (c) Plot of the turnover frequency (TOF), measured at $180{ }^{\circ} \mathrm{C}$ and $200{ }^{\circ} \mathrm{C}$, of $\mathrm{Rh}_{\mathrm{x}} \mathrm{Pt}_{1-\mathrm{x}}$ and the activation energies of nanoparticle arrays as a function of Rh composition $(x=0-1)$.

Figure 13. Schematic of in-situ monitoring of nanoparticles with (a) high pressure sum frequency generation (SFG) spectroscopy and (b) high pressure STM. 
References

1. G. Ertl and H. J. Freund, Physics Today, 1999, 52, 32-38.

2. G. Ert, H. Knözinger, J. Weitkamp, Eds.,Handbook of Heterogeneous Catalysis (Wiley-VCH, Weinheim, 1997).

3. G. A. Somorjai and J. Y. Park, Physics Today, 2007, 60, 48-53.

4. A. Stierle and A. M. Molenbroek, Mrs Bulletin, 2007, 32, 1001-1005.

5. G. A. Somorjai, R. L. York, D. Butcher and J. Y. Park, Physical Chemistry Chemical Physics, 2007, 9, 3500-3513.

6. H. J. Freund, H. Kuhlenbeck, J. Libuda, G. Rupprechter, M. Baumer and H. Hamann, Topics in Catalysis, 2001, 15, 201-209.

7. L. Osterlund, P. B. Rasmussen, P. Thostrup, E. Laegsgaard, I. Stensgaard and F. Besenbacher, Physical Review Letters, 2001, 86, 460-463.

8. G. A. Somorjai, Introduction to Surface Chemistry and Catalysis, Wiley, New York 1994.

9. G. D. Stucky and J. E. Macdougall, Science, 1990, 247, 669-678.

10. C. T. Kresge, M. E. Leonowicz, W. J. Roth, J. C. Vartuli and J. S. Beck, Nature, 1992, 359, 710-712.

11. N. Toshima and T. Yonezawa, New Journal of Chemistry, 1998, 22, 1179-1201.

12. R. Narayanan and M. A. El-Sayed, Nano Letters, 2004, 4, 1343-1348.

13. J. Grunes, J. Zhu, M. C. Yang and G. A. Somorjai, Catalysis Letters, 2003, 86, 157-161.

14. G. A. Somorjai and J. Y. Park, Catalysis Letters, 2007, 115, 87-98.

15. B. Bhushan, J. N. Israelachvili and U. Landman, Nature, 1995, 374, 607-616.

16. J. Y. Park, D. F. Ogletree, P. A. Thiel and M. Salmeron, Science, 2006, 313, 186-186.

17. Sabatier, P., Kataliz v organicheskoi khimii (Catalysis in Organic Chemistry), Orlov, N.A. and Petrov, A.D., Eds. and authors of supplements, Leningrad: Goskhimtekhizdat, 1932.

18. P. Sabatier, Industrial and Engineering Chemistry, 1926, 18, 1005-1008.

19. C. T. Campbell, Surface Science Reports, 1997, 27, 1-111.

20. C. B. Duke, Chemical Reviews, 1996, 96, 1237-1259.

21. G. A. Somorjai, K. M. Bratlie, M. O. Montano and J. Y. Park, Journal of Physical Chemistry B, 2006, 110, 20014-20022.

22. M.A. Van Hove, W.H. Weinberg and C.-M. Chan, Low-Energy Electron Diffraction, Springer Verlag, 1986.

23. J.B. Pendry, Low Energy Electron Diffraction, Academic Press, 1974.

24. S. Hagstrom, H. B. Lyon and G. A. Somorjai, Physical Review Letters, 1965, $15,491$.

25. L. L. Kesmodel, L. H. Dubois and G. A. Somorjai, Chemical Physics Letters, 1978, 56, 267-271.

26. S. L. Bernasek and G. A. Somorjai, Journal of Chemical Physics, 1975, 62, 3149-3161.

27. M. Salmeron, R. J. Gale and G. A. Somorjai, Journal of Chemical Physics, 1979, 70, 2807-2818. 
28. N. D. Spencer, R. C. Schoonmaker and G. A. Somorjai, Journal of Catalysis, 1982, 74, 129-135.

29. Y. R. Shen, Annual Review of Physical Chemistry, 1989, 40, 327-350.

30. X. C. Su, P. S. Cremer, Y. R. Shen and G. A. Somorjai, Journal of the American Chemical Society, 1997, 119, 3994-4000.

31. P. S. Cremer, X. C. Su, Y. R. Shen and G. A. Somorjai, Journal of the American Chemical Society, 1996, 118, 2942-2949.

32. G. Rupprechter, Mrs Bulletin, 2007, 32, 1031-1037.

33. Z. Chen, D. H. Gracias and G. A. Somorjai, Applied Physics B-Lasers and Optics, 1999, 68, 549-557.

34. S. J. Kweskin, R. M. Rioux, S. E. Habas, K. Komvopoulos, P. Yang and G. A. Somorjai, Journal of Physical Chemistry B, 2006, 110, 15920-15925.

35. B. J. McIntyre, M. Salmeron and G. A. Somorjai, Journal of Vacuum Science \& Technology a-Vacuum Surfaces and Films, 1993, 11, 1964-1968.

36. B. L. M. Hendriksen and J. W. M. Frenken, Physical Review Letters, 2002, 89, 046101.

37. M. Montano, M. Salmeron and G. A. Somorjai, Surface Science, 2006, 600, 1809-1816.

38. K. M. Bratlie, M. O. Montano, L. D. Flores, M. Paajanen and G. A. Somorjai, Journal of the American Chemical Society, 2006, 128, 12810-12816.

39. S. L. Yau, Y. G. Kim and K. Itaya, Journal of the American Chemical Society, 1996, 118, 7795-7803.

40. S. R. Longwitz, J. Schnadt, E. K. Vestergaard, R. T. Vang, E. Laegsgaard, I. Stensgaard, H. Brune and F. Besenbacher, Journal of Physical Chemistry B, 2004, 108, 14497-14502.

41. H. Lee, S. E. Habas, S. Kweskin, D. Butcher, G. A. Somorjai and P. D. Yang, Angewandte Chemie-International Edition, 2006, 45, 7824-7828.

42. H. Song, R. M. Rioux, J. D. Hoefelmeyer, R. Komor, K. Niesz, M. Grass, P. D. Yang and G. A. Somorjai, Journal of the American Chemical Society, 2006, 128, 3027-3037.

43. R. M. Rioux, H. Song, M. Grass, S. Habas, K. Niesz, J. D. Hoefelmeyer, P. Yang and G. A. Somorjai, Topics in Catalysis, 2006, 39, 167-174.

44. G. A. Somorjai and R. M. Rioux, Catalysis Today, 2005, 100, 201-215.

45. C. Mohr, H. Hofmeister, J. Radnik and P. Claus, Journal of the American Chemical Society, 2003, 125, 1905-1911.

46. K. M. Bratlie, H. Lee, K. Komvopoulos, P. Yang and G. A. Somorjai, Nano Letters, 2007, 7, 3097-3101.

47. K. M. Bratlie, C. J. Kliewer and G. A. Somorjai, Journal of Physical Chemistry B, 2006, 110, 17925-17930.

48. Y. Zhang, M. E. Grass, S. E. Habas, F. Tao, T. Zhang, P. Yang and G. A. Somorjai, Journal of Physical Chemistry C, 2007, 111, 12243-12253.

49. J. Y. Park, Y. Zhang, M. Grass, T. Zhang and G. A. Somorjai, Nano Letters, 2008, 8, 673 -677.

50. A. V. Kalinkin, A. V. Pashis and V. I. Bukhtiyarov, Reaction Kinetics and Catalysis Letters, 2003, 78, 121-127. 
51. C. H. F. Peden, D. W. Goodman, D. S. Blair, P. J. Berlowitz, G. B. Fisher and S. H. Oh, Journal of Physical Chemistry, 1988, 92, 1563-1567.

52. W. M. Daniel, Y. Kim, H. C. Peebles and J. M. White, Surface Science, 1981, 111, 189-204.

53. C. R. Helms, H. P. Bonzel and S. Kelemen, Journal of Chemical Physics, 1976, 65, 1773-1782.

54. A. D. Vanlangeveld and J. W. Niemantsverdriet, Surface Science, 1986, 178, 880-887.

55. K. M. Bratlie, K. Komvopoulos and G. A. Somorjai, unpublished. 
(a)

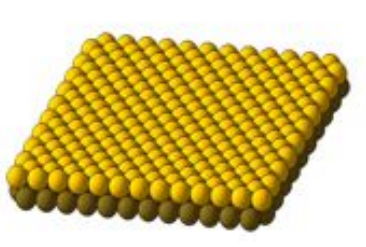

fcc (111)

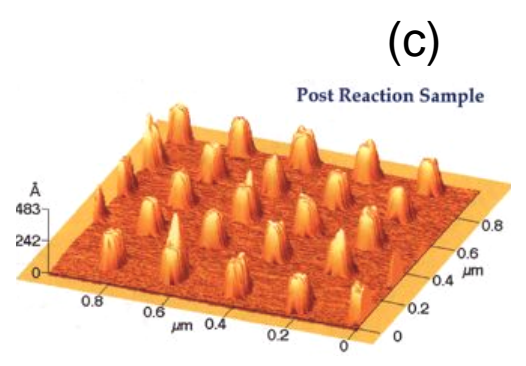

Pt nanoparticles on silicon oxide (b)

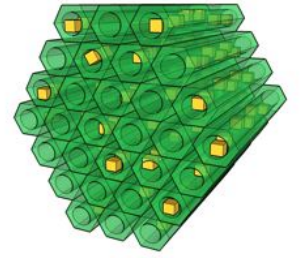

Nanoparticles in

mesoporous

Silica (SBA-15)

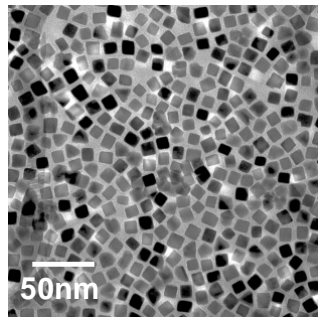

Colloid Pt

nanoparticles

Figure 1. 


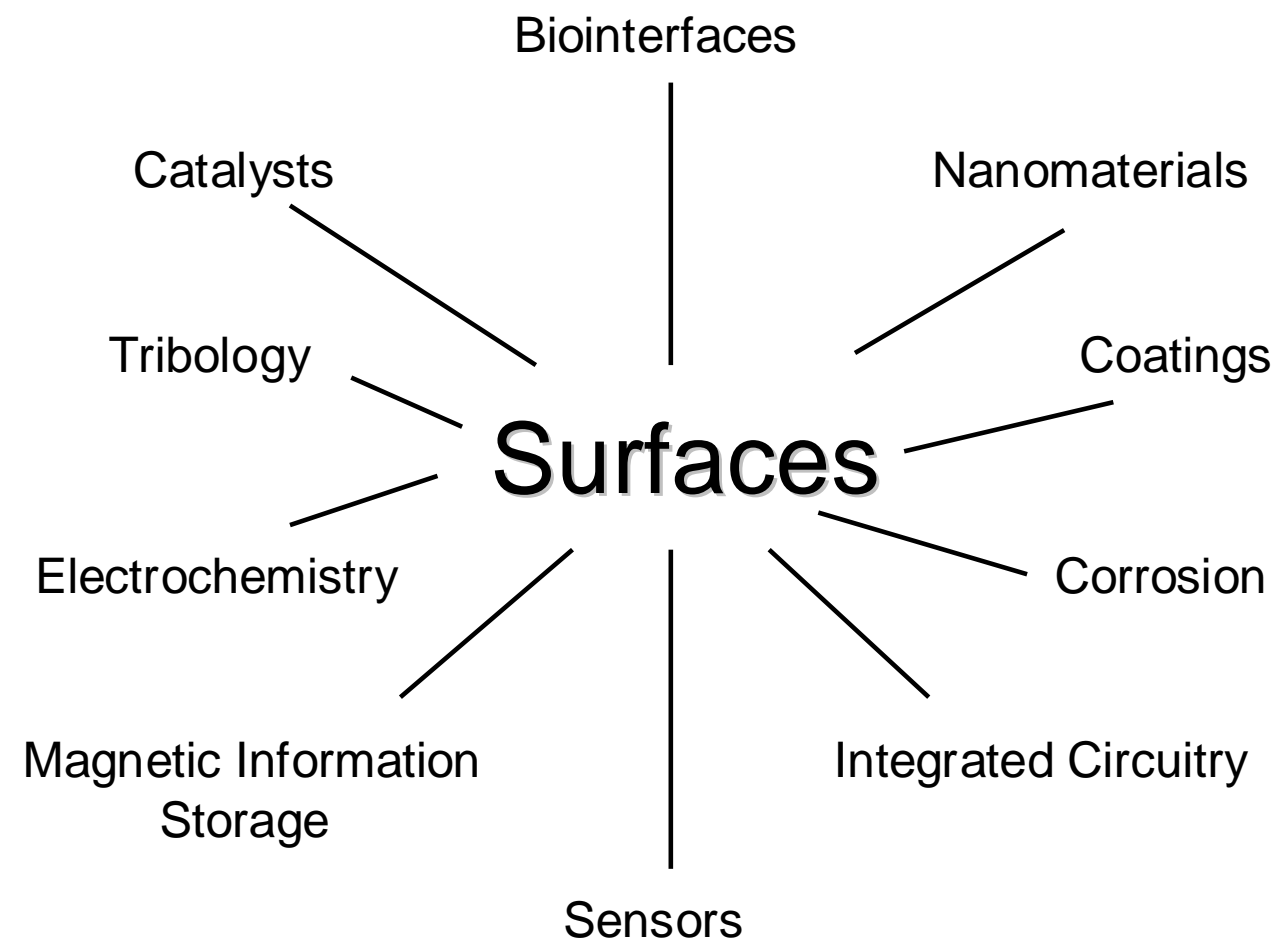

Figure 2. 
(a)

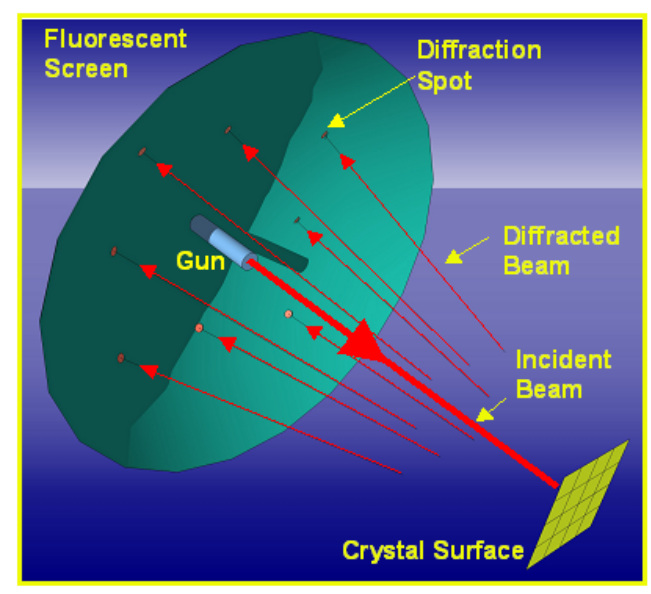

(b)
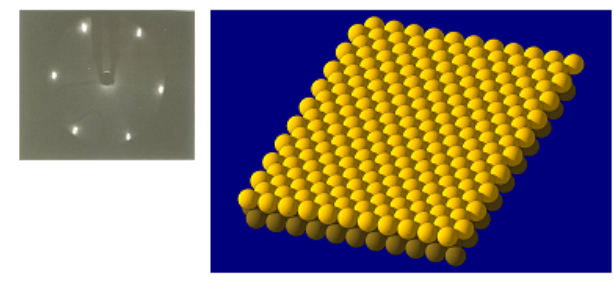

Pt (111)
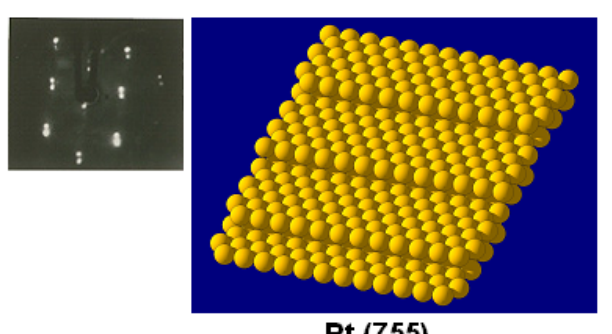

Figure 3. 
(a)

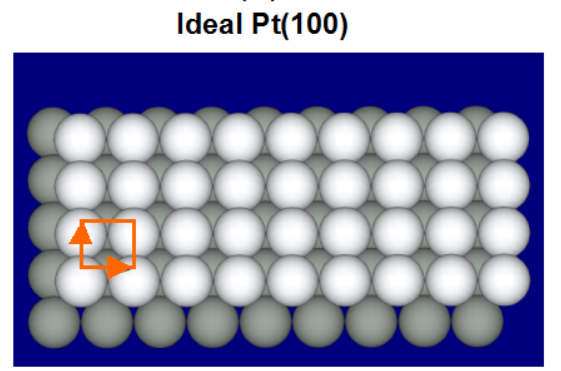

Reconstructed

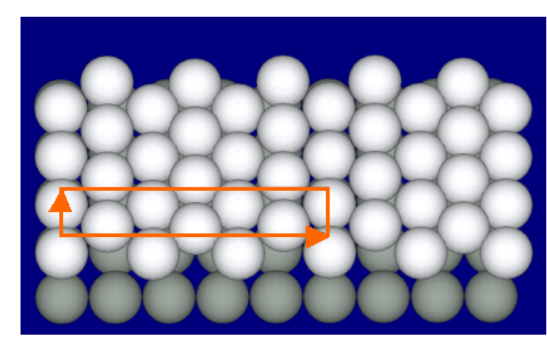

(b)

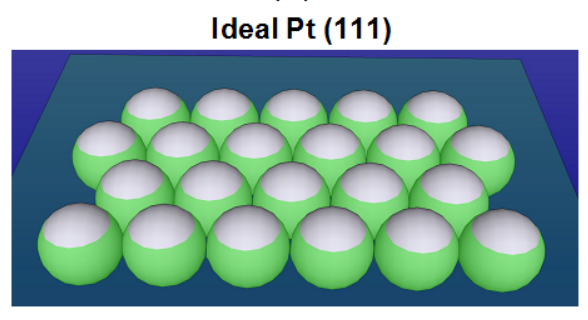

Ethylidyne on Pt (111)

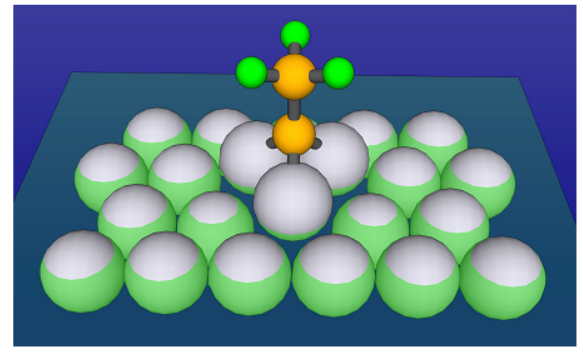

Figure 4. 
(a)

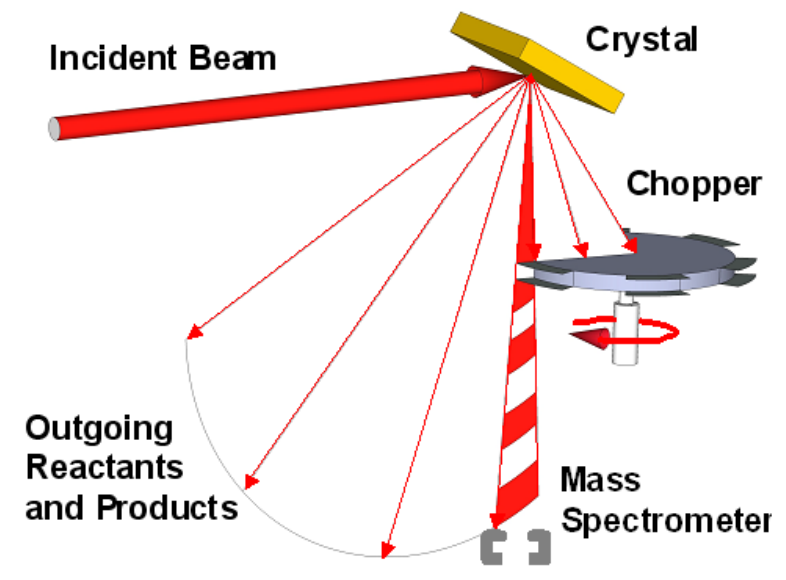

(b)

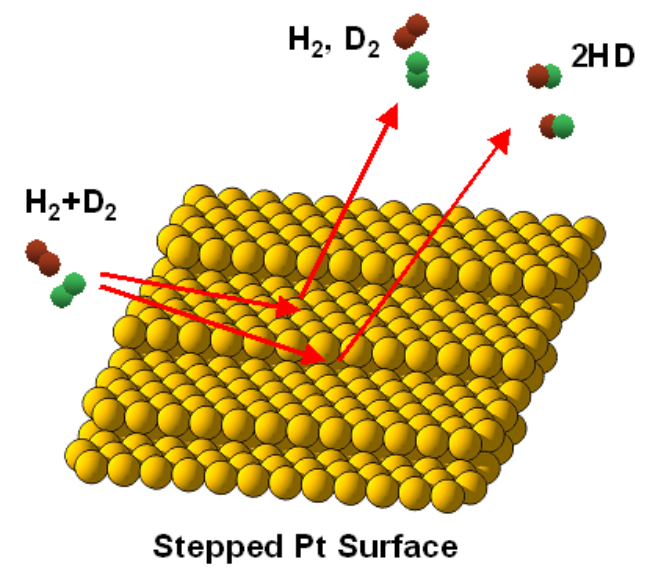

Figure 5. 
(a)

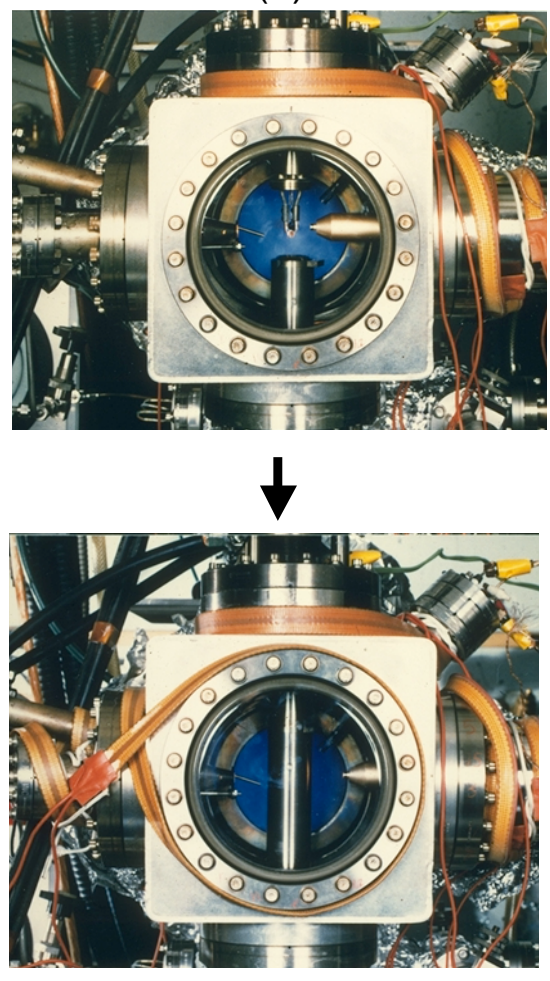

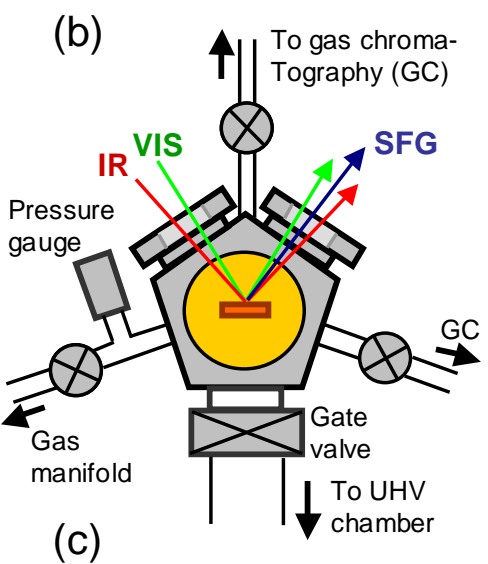

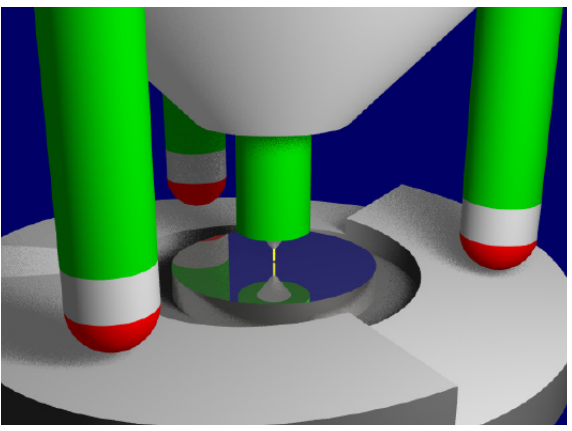

Figure 6. 
(a)

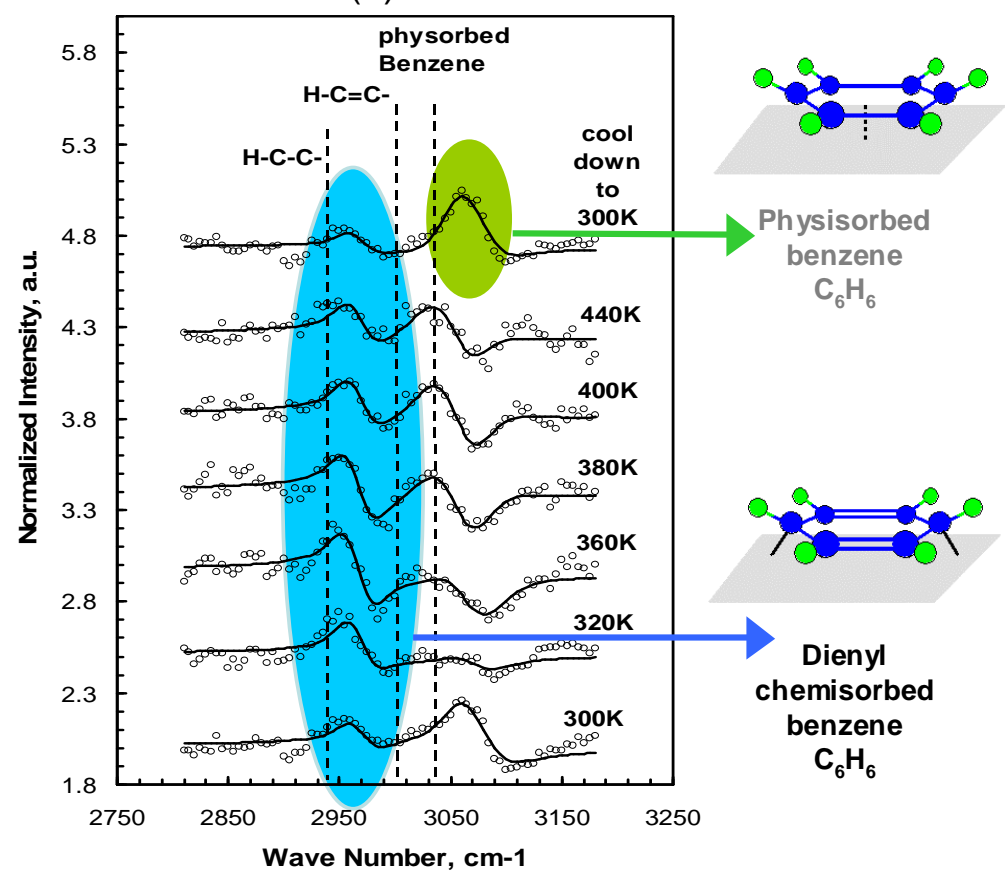

(b)

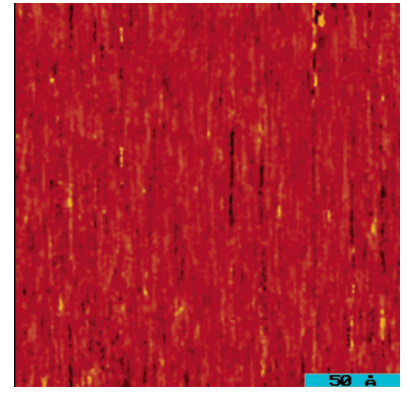

(c)

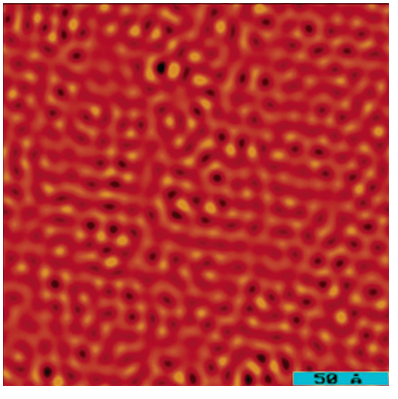

Figure 7. 
Metal single crystal surface

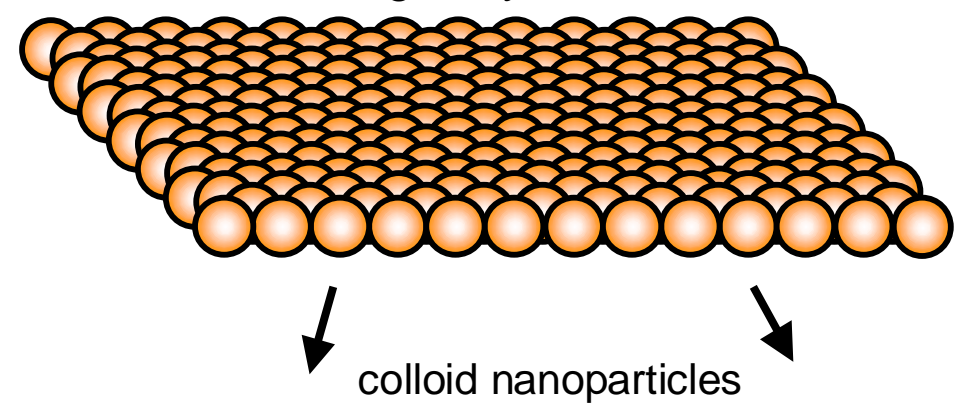

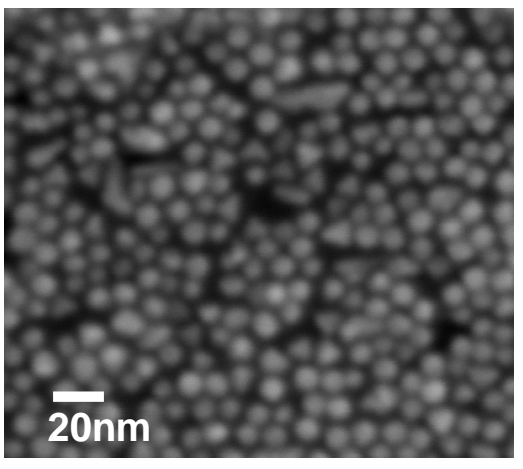

2D Pt nanoparticle arrays on silicon surface

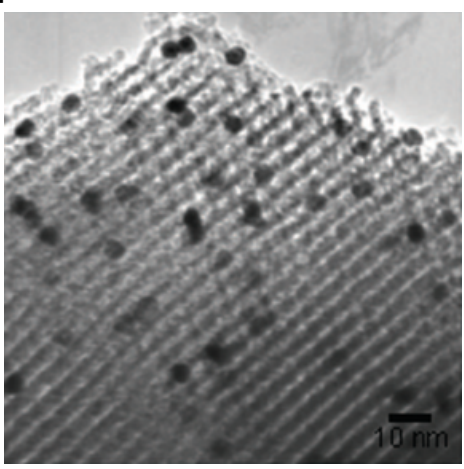

3D nanoparticle array $(7.1 \mathrm{~nm}$ Pt nanoparticles in SBA-15)

Figure 8. 
(a)
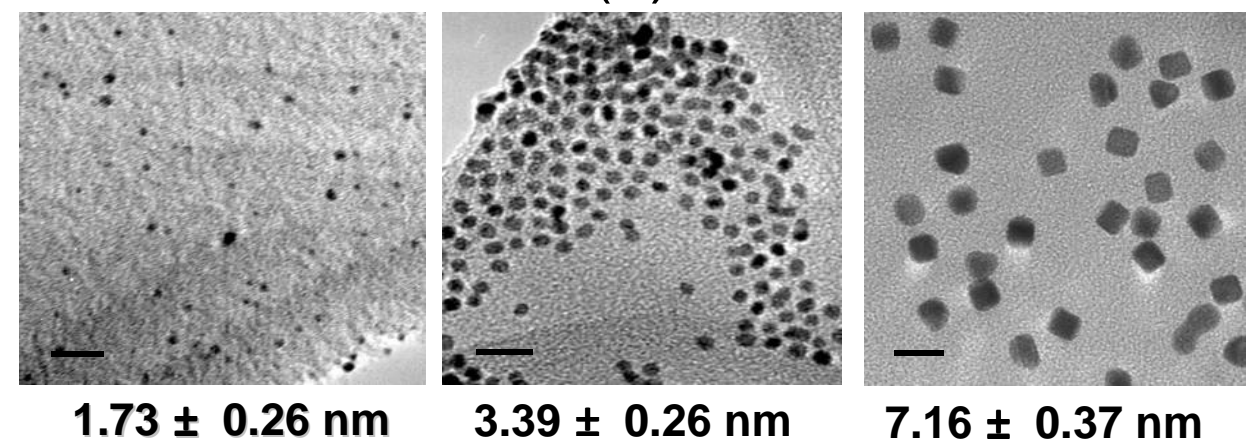

$3.39 \pm 0.26 \mathrm{~nm}$

$7.16 \pm 0.37 \mathrm{~nm}$

(b)

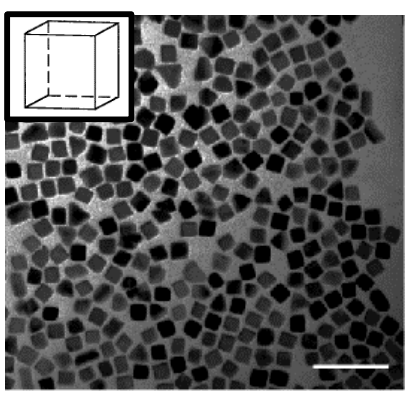

Cube

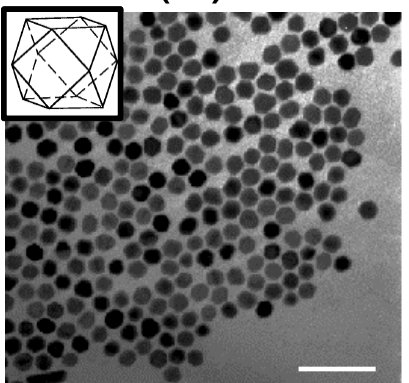

Cuboctahedra

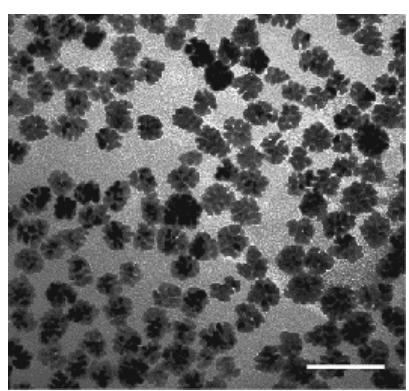

Porous particle

Figure 9. 
(a)

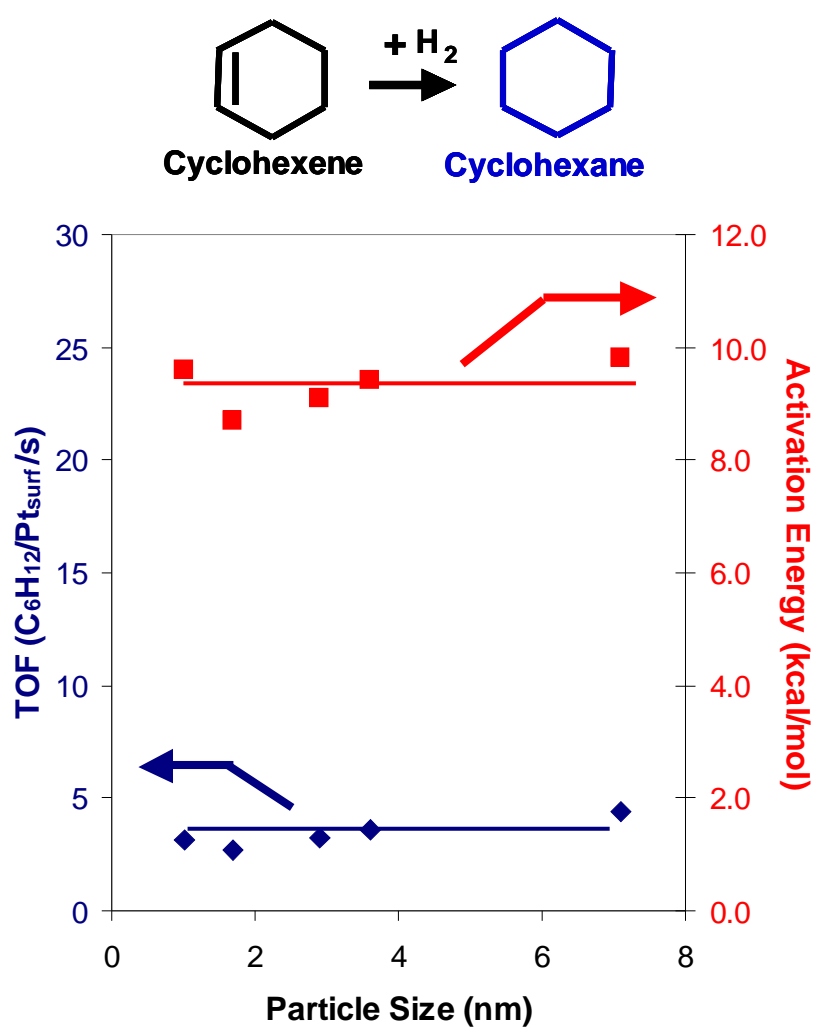

(b)

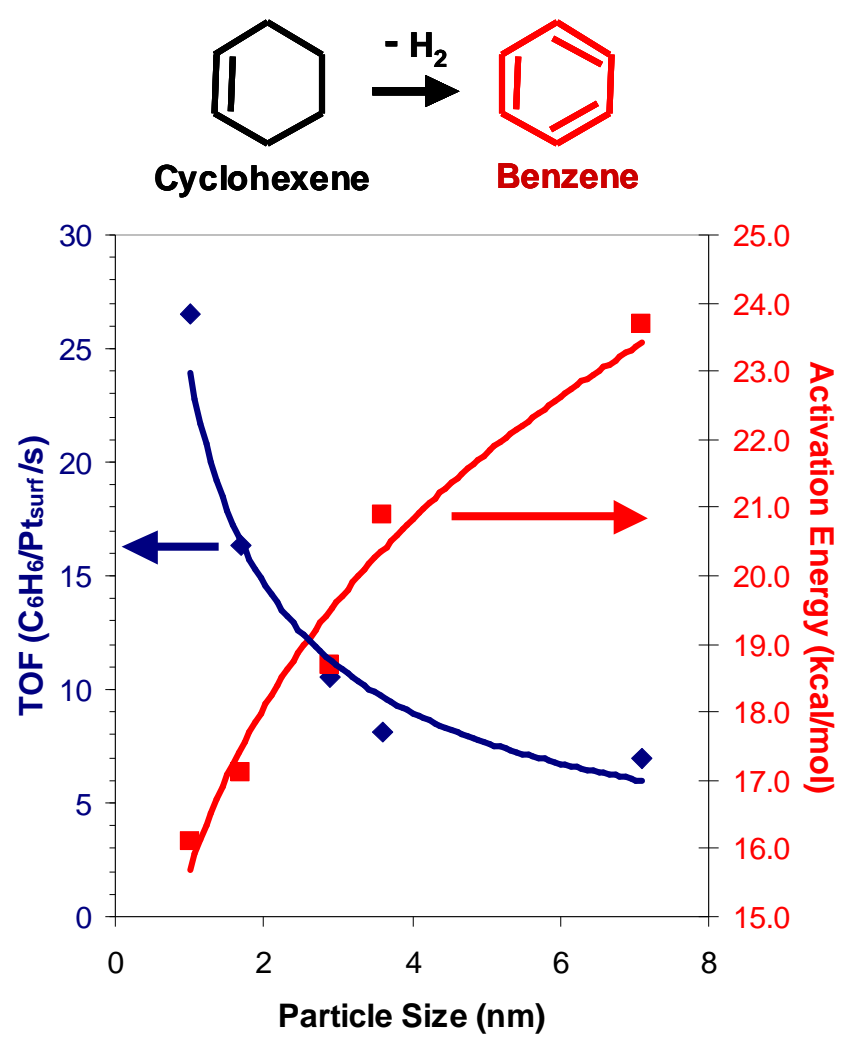

Figure 10. 

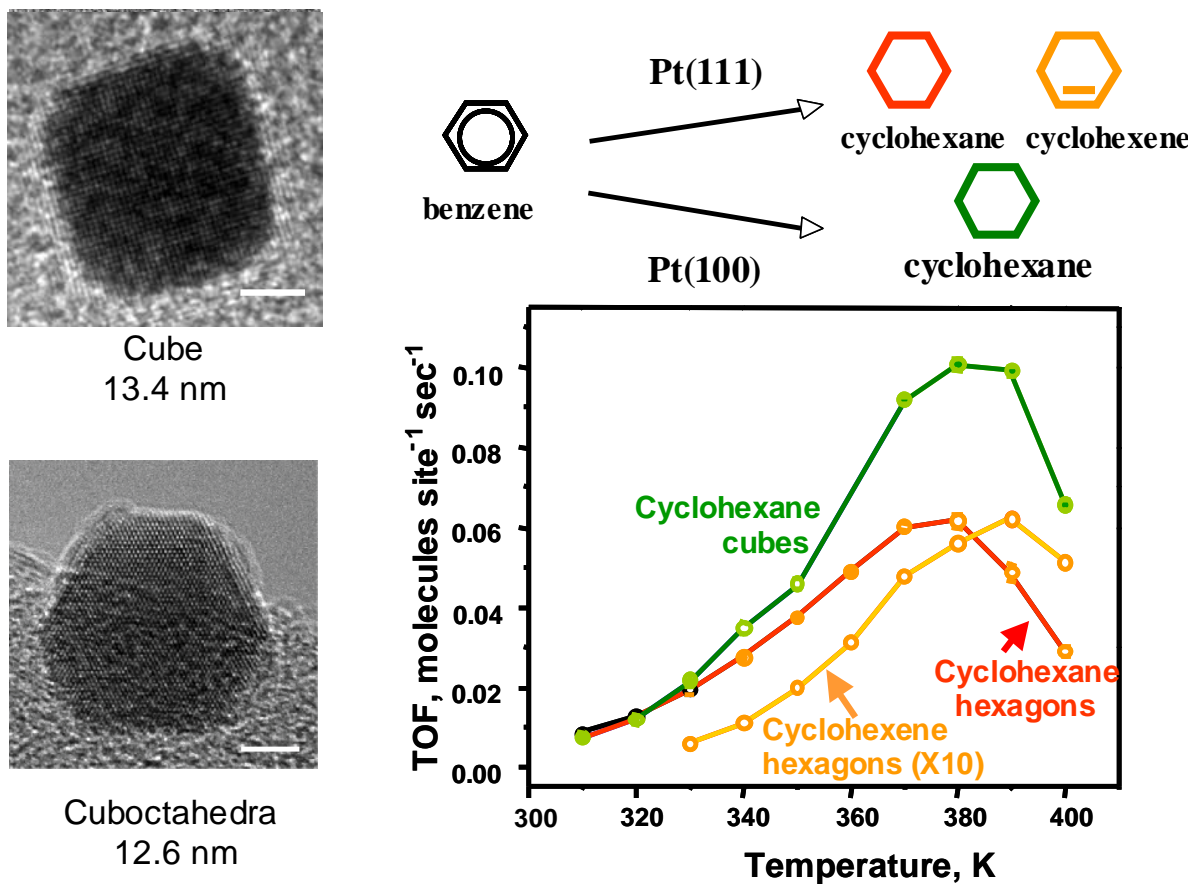

Figure 11. 
(a)

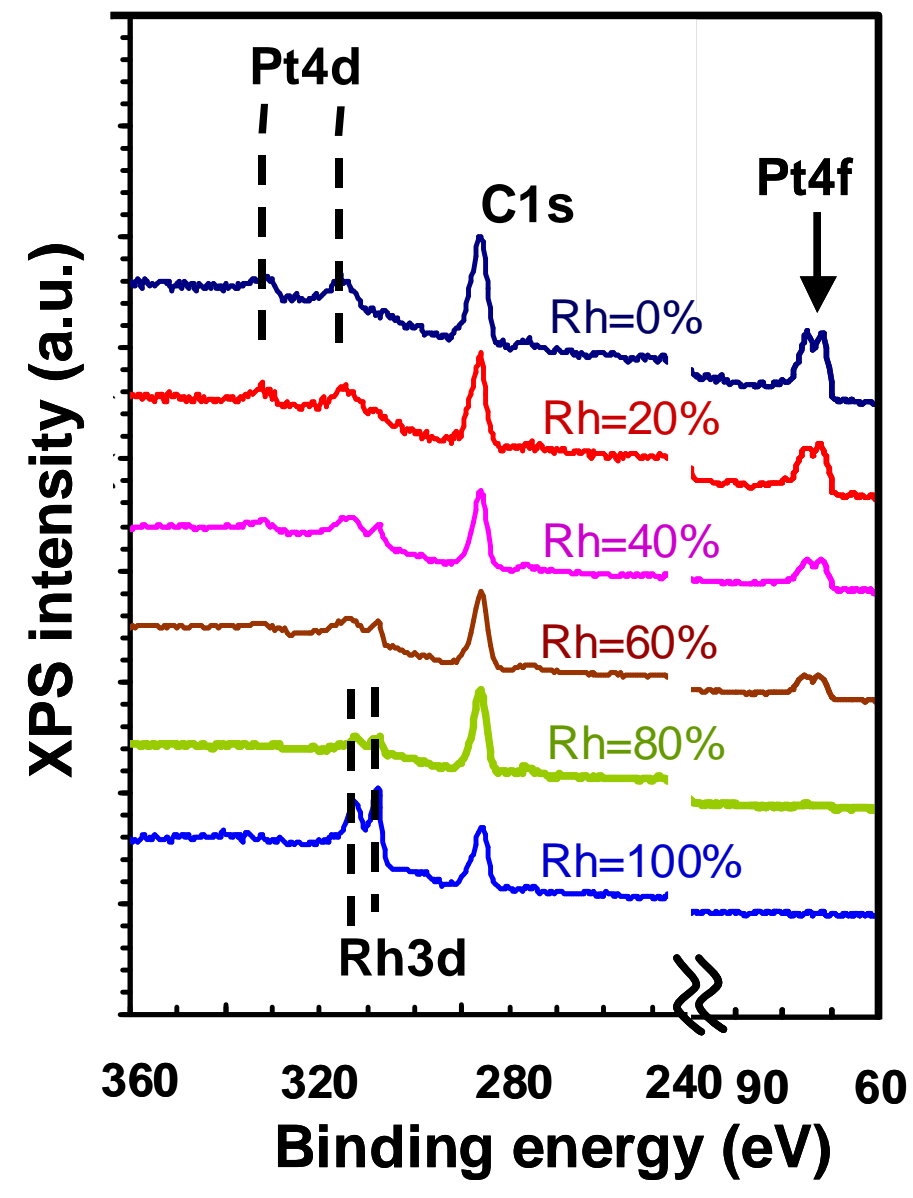

(b)

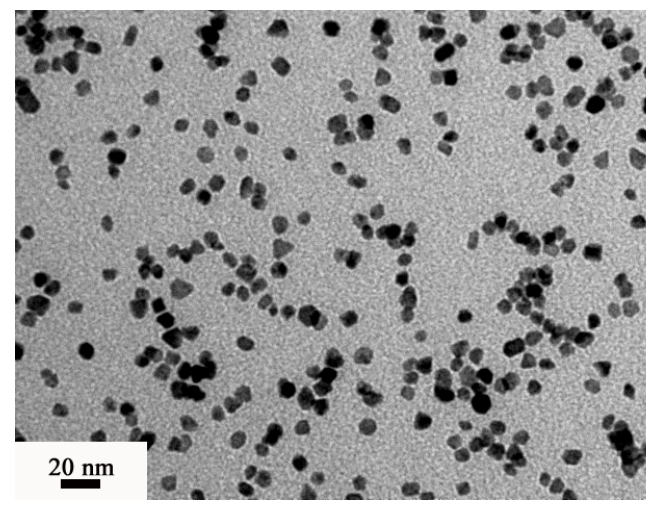

(c)

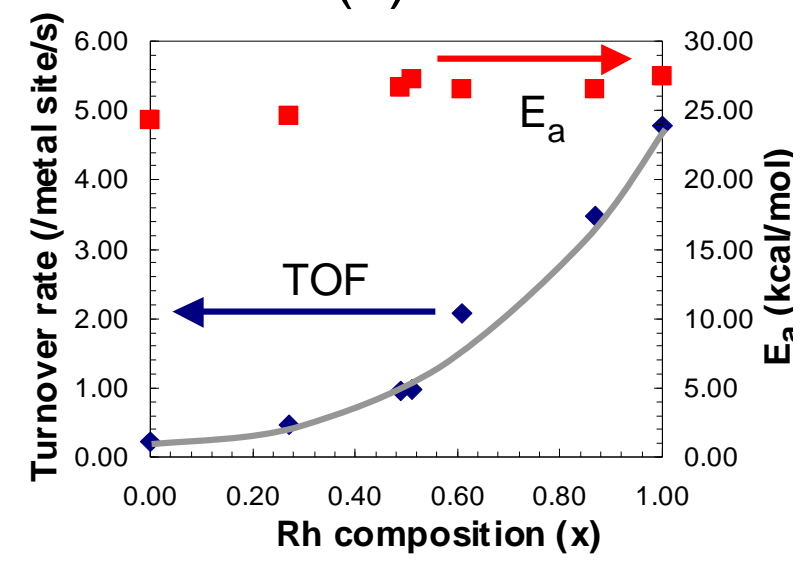

Figure 12. 

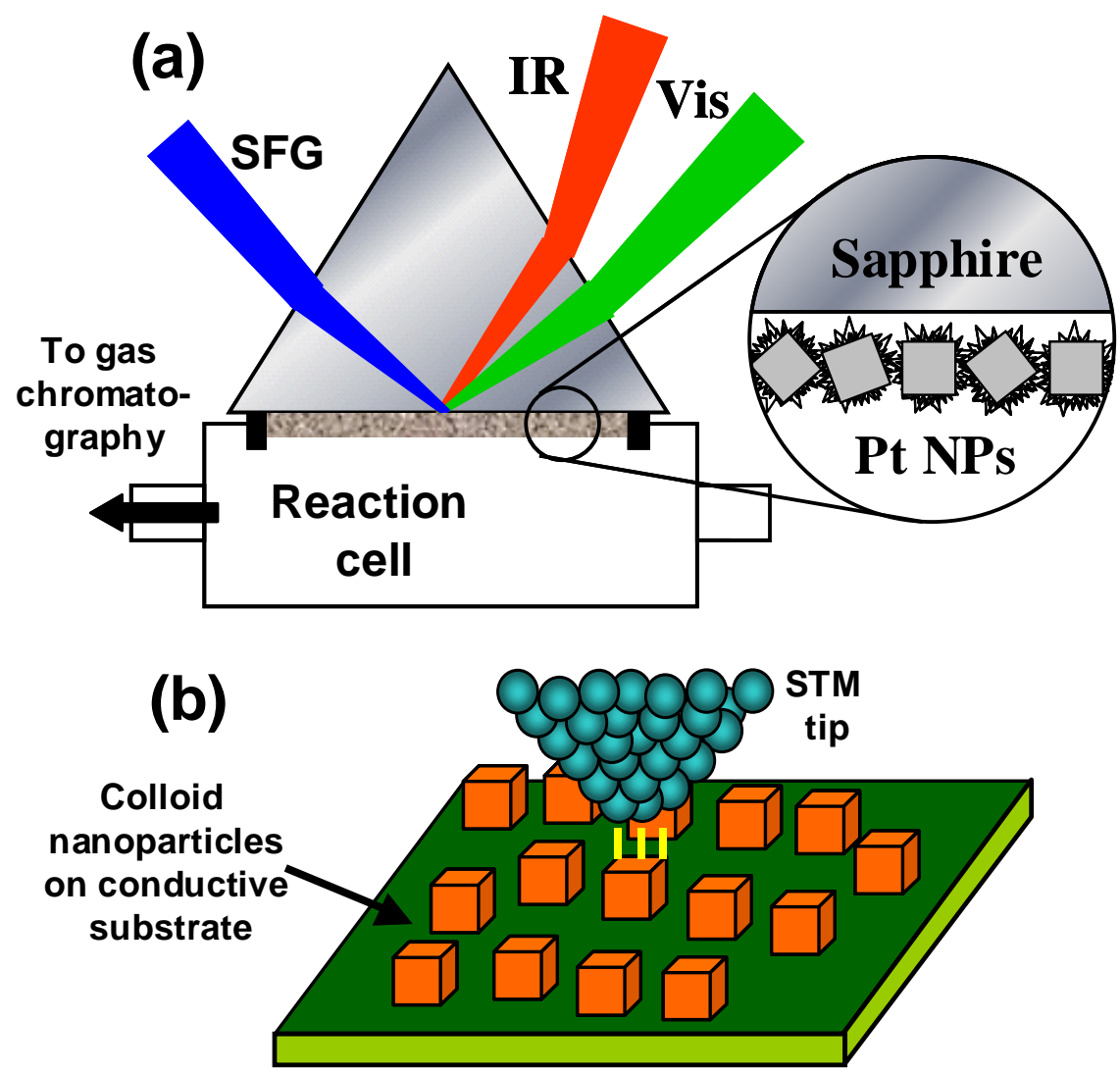

Figure 13. 